\title{
MINAT MAHASISWA PROGRAM STUDI D4 MANAJEMEN PERHOTELAN JURUSAN PARIWISATA FAKULTAS PARIWISATA DAN PERHOTELAN UNIVERSITAS NEGERI PADANG MELAKSANAKAN PENGALAMAN LAPANGAN INDUSTRI DI INTERNATIONAL CHAIN HOTEL
}

\author{
Junita Riza, Ira Meirina Chair \\ Program Studi D4 Manajemen Perhotelan \\ Jurusan Pariwisata \\ Fakultas Pariwisata dan Perhotelan Universitas Negeri Padang \\ email: riza.junita23@gmail.com
}

\begin{abstract}
This study aims to determine the interest of D4 hospitality management study program students in tourism and hospitality faculties of Padang State University to carry out industry experience in international chain hotel. This type of research is quantitative descriptive with survey methods. Samples were taken using purposive sampling technique with 83 respondents used questionnaires on the Guttmann scale. Based on the research that has been done, the results are as follows: (1) feeling happy in the very high category (59,03\%), (2) attraction is in the very high category (50,60\%), (3) attention is in high category (42,16\%) and involvement is in the very high category $(44,57 \%)$.
\end{abstract}

Keywords: Interest, Industrial Field Experience, International Chain Hotel

\section{PENDAHULUAN}

Dalam beberapa dekade terakhir, peranan industri hospitality menjadi semakin penting terhadap kemajuan ekonomi dan sosial dimana berkontribusi besar terhadap terciptanya Produk Domestik Bruto(Gross Domestic Product) dan lapangan pekerjaan, sehingga memperkuat perekonomian sosial (Cut-Lupulescu,Dincu, \& Borlovan, 2014). Terutama Negara-negara berkembang lebih merasakan dampak dari industri hospitality, termasuk Indonesia. Pada tahun 2017, lebih dari 4,5 juta pekerjaan atau $3,7 \%$ dari total pekerjaan di Indonesia berasal dari industri pariwisata yang terdiri dari segmen akomodasi, makanan dan minuman (food and beverage, retail, transportasi dan rekreasi (WTTC, 2018). Selain itu, diperkirakan kedatangan turis internasional akan mencapai 1,8 miliar pada tahun 2030 dengan tingkat pertumbuhan sebesar $3,3 \%$ setiap tahunnya
(UNWTO, 2017). Dari sini dapat dilihat bahwa industri ini masih akan terus berkembang kedepannya.

Kusulvan (2000) menyatakan betapa pentingnya bagi industri hospitality untuk memiliki tenaga kerja yang terampil, antusias dan berkomitmen karena sebagian besar pelayanan yang diberikan di sektor ini didasarkan pada kinerja manusia dalam kondisi saling bertatap muka.Untuk tercapainya hal itu, penting bagi calon tenaga kerja untuk mendapat pendidikan dan pengetahuan yang cukup.

Pendidikan yang dimaksud bisa didapat melalui berbagai institusiPendidikan di Indonesia yang setiap tahunnya memproduksi dan menyumbang ratusan bahkan ribuan calon pekerja terhadap industri hospitality.Salah satunya adalah Universitas Negeri Padang (UNP) yang menawarkan pengetahuan dan keahlian yang dibutuhkan dalam mengelola bisnis di 


\section{JPK Unum

industri hospitality, yaitu keahlian manajerial, operasional hotel, hubungan interpersonal serta kemampuan berbahasa asing.

Universitas Negeri Padang (UNP) merupakan lembaga pendidikan yang berfungsi untuk mempersiapkan tenaga pendidikan dan non kependidikan yang dapat meningkatkan kualitas dan mutu sumber daya manusia yang dibekali dengan kemampuan akademik dan profesional dalam mengembangkan, menerapkan, dan menciptakan ilmu pengetahuan di tanah air. Dalam buku peraturan Akademik Universitas Negeri Padang (2011:1) menyatakan bahwa:

"Universitas Negeri Padang (UNP) adalah perguruan tinggi negeri yang berada di Padang Sumatera Barat, antara lain menyelenggarakan pendidikan akademik profesi dan vokasi dalambidang kependidikan dan non pendidikan".

Berdasarkan uraian di atas dapat disimpulkan bahwa UNP berusaha meningkatkan mutu lulusannya dengan mengembangkan segala ilmu yang diperoleh, baik dibangku perkuliahan maupun lainnya melalui program lapangan, yang meliputi program pengalaman lapangan kependidikan (PPLK) dan pengalaman lapangan industri (PLI).

Sebagai aplikasi nyata dari ilmu pengetahuan yang dimiliki tersebut maka dilaksanakan Pengalaman Lapangan Industri (PLI) dengan tujuan percepatan adaptasi dengan lingkungan sehingga bias mengambil peran di dunia kerja.PLI adalah satu kegiatan intrakurikuler dalam kelompok mata kuliah bidang studi jenjang program Strata 1 (S1), Diploma 4 (D4), dan Diploma 3 (D3) pada semua jurusan di FPP UNP. Program ini merupakan mata kuliah wajib diambil oleh seluruh mahasiswa FPP UNP (Buku Pedoman PLI FPP- UNP 2016: hal 1). PLI dilaksanakan pada perusahaan/industri yang beroperasi dibidang pariwisata dan perhotelan yang relevansi dengan program studi salah satunya adalah Chain Hotel. Menurut Nadi Wijaya (2014) "International Chain Hotel adalah sekelompok hotel yang mempunyai satu nama yang sama yang telah disepakati bersama baik sebagian maupun keseluruhan dengan sistem yang sama berada di luar negeri serta memiliki anak cabang”.

Berdasarkan pengalaman penulis selama training di Hotel Mercure Padang yang merupakan salah satu dari chain hotel, penulis mendapatkan kursus bahasa Inggris dan training ke departement yang lain setiap minggunya. Berikut adalah status hotel dan sebagian jumlah mahasiswa Manajemen Perhotelan angkatan atau tahun masuk 2015 yang melaksanakan PLI di International Chain Hotel yag ada di Indonesia pada periode Januari-Juni 2017.

Berdasarkan hasil wawancara yang peneliti lakukan pada bulan Maret 2018 kepada 10 orang mahasiswa Manajemen Perhotelan tahun masuk 2015, hanya 40\% mahasiswa berminat untuk melaksankan PLI di International Chain Hotel. Karena terdapat beberapa faktor yangmembuat mahasiswa ragu dan tidak percaya diri melaksanakan pengalaman lapangan industri (PLI) di international chain hotel, seperti rendahnya penguasaan bahasa asing terutama dalam berbahasa Inggris sebagaimana yang diketahui syarat utama untuk PLI di International Chain Hotel harus

mampu berbahasa asing. Masalah lainnya yaitu jam kerja ekstra seperti pengalaman penulis pada saat PLI di International Chain Hotel.Penulis sering mengalami jam kerja sampai 14 jam tanpa salary dan penulis seringkali mendapatkan shift jumping seperti penulis mendapatkan afternoon shift dan keesokan harinya mendapatkan morning shift. Kendala lainnya, pekerjaan yang ditugaskan 


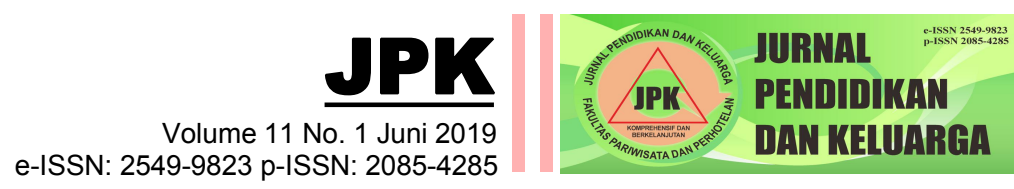

tidak sesuai dengan job desk. Sebagai contoh, penulis mendapatkan penempatan 3 bulan pertama bagian order taker pada departemen housekeeping yang mana diketahui job order taker adalah menindaklanjuti informasiinformasi yang diterima dari tamu maupun dari departemen lain dan mengerjakan segala hal administrasi dan pembukuan Housekeeping.

Sedangkan pada saat penulis melaksanakan PLI di hotel tersebut, penulis mengerjakan job desk dari public area seperti vacuum cleaning seluruh lantai hotel, membersihkan kantin, membersihkan toilet karyawan dan tamu sehingga penulis sangat minim ilmu tentang order taker.Hal yang sama terjadi Pada saat penempatan bagian food and beverage product, penulis juga mendapati pekerjaan diluar job desk seperti penulis ditempatkan pada bagian garde manger, tetapi penulis ditempatkan di hot kitchen.

Dari data di atas bisa dilihat bahwa minat mahasiswa untuk melaksanakan PLI di International Chain Hotel rendah karena disamping persyaratan yang agak ketat, mahasiswa juga sering mencari informasi kepada senior-senior sehingga membuat mahasiswa kurang berminat karena mendengar informasi dari senior-senior. Untuk itu penelitian ini bertujuan mengetahui minat mahasiswa D4 manajemen perhotelan melaksanakan PLI di International chain hotel yang bermanfaat kedepannya untuk mahasiswa tersebut.

\section{METODE}

Jenis penelitian ini adalah deskriptif kuantitatif menggunakan metode survei.Populasi adalah mahasiswa program studi D4 manajemen perhotelan universitas negeri padang tahun masuk 2016 dan 2017 berjumlah 83. Teknik pengambilan sampel adalah purposive Sampling.
Jenis data penelitian yang digunakan adalah data primer dan data sekunder.Data primer diperoleh langsung dari responden dengan menyebarkan kuesioner. Selanjutnya untuk data sekunder didapat secara tidak langsung berupa data mahasiswa. Pengolahan data penelitian ini menggunakan bantuan SPSS versi 16.00.

\section{HASIL DAN PEMBAHASAN}

\section{Hasil Penelitian}

\section{a. Analisis Deskriptif}

Berikut hasil penelitian tentang minat mahasiswa dikategorikan pada tabel berikut:

\section{Tabl 1. Distribusi Frekuensi Variabel} Minat

\begin{tabular}{|c|c|c|c|}
\hline Kategori & Skor & $\mathbf{F}$ & $\begin{array}{c}\text { Persentase } \\
(\%)\end{array}$ \\
\hline $\begin{array}{c}\text { Sangat } \\
\text { Baik }\end{array}$ & $>26,05$ & 12 & 14,5 \\
\hline Baik & $\begin{array}{c}> \\
25,35- \\
< \\
26,05\end{array}$ & 5 & 6 \\
\hline Cukup & $\begin{array}{c}> \\
24,65- \\
< \\
25,35\end{array}$ & 3 & 3,6 \\
\hline Buruk & $\begin{array}{c}>23,95 \\
-< \\
24,65\end{array}$ & 8 & 9,7 \\
\hline $\begin{array}{l}\text { Sangat } \\
\text { Buruk }\end{array}$ & $\begin{array}{c}< \\
23,95\end{array}$ & 55 & 66,2 \\
\hline \multicolumn{2}{|c|}{ Total } & 83 & 100 \\
\hline
\end{tabular}

Sumber: Data primer 2018

Berdasarkan pada tabel diatas dilihat bahwa 14,5 \% responden berpendapat bahwa minat mahasiswa sangat baik, $6 \%$ menyatakan baik, 3,6 \% menyatakan cukup. 


\section{b. Uji Coba Instrumen}

1. Uji Validitas

Tabel 2. Hasil Analisis Validitas

\begin{tabular}{|c|l|l|c|c|c|}
\hline Variabel & Indikator & \multirow{2}{*}{ No Item } & $\begin{array}{l}\text { Jumlah } \\
\text { Item }\end{array}$ & $\begin{array}{l}\text { Jumlah } \\
\text { Gugur }\end{array}$ & $\begin{array}{l}\text { Jumlah } \\
\text { Valid }\end{array}$ \\
\hline \multirow{4}{*}{ Minat } & Perasaan senzang & $1,2,3,4$ & 4 & 1 & 3 \\
\cline { 2 - 6 } & Ketertarikan & $5,6,7,8,9$ & 5 & 1 & 4 \\
\cline { 2 - 6 } & Perhatian & $10,11,12,13,14$ & 5 & 1 & 4 \\
\cline { 2 - 6 } & Keterlibatan & $15,16,17,18,19$ & 5 & 0 & 5 \\
\hline \multicolumn{2}{|c|}{ Jumlah } & 19 & 3 & 16 \\
\hline
\end{tabular}

c. Uji Reliabilitas

Tabel 3. Reliability Statistics

\begin{tabular}{|l|l|}
\hline Cronbach's Alpha & N of Items \\
\hline .622 & 16 \\
\hline
\end{tabular}

\section{Pembahasan}

Berdasarkan hasil penilaian dari 83 sampel dengan 16 butir pernyataan, maka responden berpendapat bahwa minat mahasiswa melaksanakan PLI di international chain hotel tergolong sangat baik.

Setelah dilakukan analisis pada uji coba dengan menggunakan 30 sampel untuk mahasiswa Manajemen Perhotelan 2016, diperoleh harga Cronbach's Alphapada variabel minat mahasiswa sebanyak 0,622. Jumlah hasil tersebut menunjukkan bahwa koefisien yang telah dilakukan uji coba memiliki tingkat reliabilitas yang tinggi.

Jika mahasiswa memiliki perasaan senang yang sangat tinggi terhadap sesuatu tersebut, maka dengan sendirinya mahasiswa tersebut tertarik, perhatian dan ingin terlibat langsung.Hal ini akan berdampak baik pada diri mahasiswa untuk melaksanakan PLI di international chain hotel. Menurut Djaali (2008:121), menyatakan bahwa "Minat dapat diekspresikan melalui pernyataan yang menunjukkan bahwa siswa lebih menyukai suatu hal, sehingga siswa menjadi tertarik, memiliki perasaan senang, perhatian sehingga menjadi butuh dengan hal tersebut bahkan minat dapat pula dimanifestasikan melalui partisipasi dalam suatu aktifitas".

\section{PENUTUP}

\section{Simpulan}

Berdasarkan data dan hasil penelitian dan pembahasan yang telah dilakukan pada bagian sebelumnya mengenai "Minat Mahasiswa Program Studi D4 Manajemen Perhotelan Jurusan Pariwisata Fakultas Pariwisata dan Perhotelan Universitas Negeri Padang melaksanakan Pengalaman Lapangan Industri Di International Chain Hotel", maka dapat disimpulkan minat mahasiswa $14,5 \%$ sangat baik, $6 \%$ menyatakan baik, 3,6\% menyatakan cukup.

\section{Saran}

Dalam penelitian skripsi ini penulis menyadari penelitian ini belum sempurna dan masih banyak terdapat kekurangan di dalam penulisan ini, untuk itu peneliti menyarankan:

a. Kepada Unit Hubungan Industri (UHI) Diharapkan kepada UHI untuk lebih memperbanyak lagi kerja sama dengan international chain hotel agar mahasiswa lebih banyak pertimbangan terhadap tempat pelaksanaan PLI yang mereka inginkan.

b. Kepada Jurusan Pariwisata

Diharapkan kepada jurusan pariwisata untuk membekali mahasiswa dalam menghadapi PLI dengan meningkatkan keterampilan pada saat perkuliahan seperti front office, tata graham, restaurant, dan lain-lain agar 
mahasiswa tidak canggung pada saat pelaksanaan PLI.

c. Kepada mahasiswa yang akan melaksanakan PLI

Diharapkan kepada mahasiswa yang akan melaksanakan PLI agar lebih mempersiapkan diri khususnya dalam penguasaan bahasa asing, pengetahuan, dan keterampilan, mental kesehatan dan lain-lain untuk menghadapi dunia industri khususnya di jurusan pariwisata.

\section{DAFTAR PUSTAKA}

Anonim, A Report produced for the Research Group of the European Travel Comission (ETC) and for the World Tourism Organization (WTO). World Tourism Organization (WTO). Spain.

Buku Pedoman Akademik UNP (2011:12)

Djaali.2013.Psikologi Pendidikan.. Jakarta: Bumi Aksara.

Safari. 2003 . Indikator Minat Belajar. Jakarta:Rineka Cipta

Sugiyono.2006.Metode Penelitian Kuantitatif, Kualitatif dan R\&D.Bandung:Alfabetas .2012.Metode Penelitian Kuantitatif Kualitatif dan R\&D.Bandung:Alfabeta 2013.Metode Penelitian Kuantitatif, Kualitatif dan R\&D.Bandung:Alfabeta .2014.Metode Penelitian Pendidikan Pendekatan Kuantitatif, Kualitatif, dan $R \& D$.Bandung:Alfabeta

Widiastuti. 2009. Pengaruh Motivasi Terhadap Minat Mahasiswa untuk mengikuti Pendidikan Profesi Akuntansi 